\title{
Automatic Germination Evaluation and Qualitative Analysis of Essential Oil of Mentha $\times$ piperita L. under the Influence of High Frequency Pulsatile Electromagnetic and Ultrasound Pulsatile Fields
}

\author{
Valentin SINGUREANU ${ }^{1 *}$, Rodica UNGUR ${ }^{2}$, Ioan ONAC ${ }^{2}$, Melinda Haydee KOVACS 3 , \\ Gelu MOLDOVAN ${ }^{1}$, Victoria SINGUREANU ${ }^{4}$
}

\author{
${ }^{1}$ University of Agricultural Sciences and Veterinary Medicine, 3-5 Manastur St., 400372, Cluj-Napoca, \\ Romania;valentin.singureanu@usamvcluj.ro("correspondingauthor);gelumoldo@yahoo.com \\ 2"Iuliu Hațieganu”University of Medicine and Pharmacy Cluj-Napoca, 8 Victor BabeşStr., Cluj-Napoca, Romania; ungurmed@yahoo.com; ioan.onac@umfcluj.ro \\ 3INCDO-INOE2000, Research Institutefor Analytical Instrumentation(ICLA),67Donath Str., 400293, Cluj-Napoca, Romania; melinda.kovacs@icia.ro \\ ${ }^{4}$ RehabilitationClinical Hospital Cluj-Napoca, 46-50ViilorStr.,Cluj-Napoca, Romania; vickituns@yahoo.com
}

\begin{abstract}
The study illustrates the influence of high frequency pulsatile electromagnetic fields and ultrasound pulsatile fields on Mentha $\times$ piperita L. seed germination and the quality of its essential oil. The physiological role of the above mentioned experimental factors was considered to be a catalyticall base point, improving germination percent, SVI (seedling vigor index), GVI (germination velocity index). All the biometric aspects of the germination process (seed area, seed perimeter, seed development on $\mathrm{x}$ and $\mathrm{y}$ radius, radicele length, hypocotyl length) where determined using open free software, consolidating the general idea that scientific communities can improve and perfect open source projects. High frequency pulsatile electromagnetic fields $(91.75 \%)$ and ultrasound pulsatile fields (64.75\%) experimental variants gave higher germination percent compared to control (47.00\%). Following the main terpenes determination, the same experimental variants obtained high accumulations of menthol, eugenol, thymol, eucalyptol, linalool and other components. These aspects can be scientifically sustained by the seedling vigor index marks obtained at high frequency pulsatile electromagnetic fields (1985.47) and ultrasound pulsatile fields (1480.09), creating the general premises for better development stages in the nursery sector. Raised accumulation of main therapeutical terpenes in Mentha $\times$ piperita L. must be supervised in further studies, when microscopically imagery of glandular trichomes and their density may lead to more profound conclusions.
\end{abstract}

Keywords: open source, catalyst, terpenes, raster image, vector image

\section{Introduction}

Peppermint (Mentha $\times$ piperita L.), a spontaneous (hexaploid) sterile hybrid between Mentha spicata and water mint Mentha aquatica, generated over 250 years ago (Kumar $e t$ al., 2014; Murray et al., 1972), belonging to Lamiaceae family, is distributed widely in temperate and sub-temperate climatic regions. It is generally used for multiple bio-resources purposes such as: flavor ingredient, antioxidant, antimicrobial, nutraceutical, herbicide, biocide and repellent (D'Antuono and Elementi, 2006; Freire et al., 2012; Pistrick, 2006; Saeed and Tariq 2005). Weak germination percentage and low field emergence represent main problems of Mentha $\times$ piperita $\mathrm{L}$. (Adkins et al., 2007; Estrelles et al., 2004; Parra et al., 2014) cultivation. Although vegetative propagation represents the key solution for uniform and constant yields, seed propagation consists as a minimum input solution where thousands of plants can be easily propagated in a small surface. In order to assist the general announced idea, a possible solution is represented by environmental friendly technologies based on physical and biological treatments that increase germination rate, seedling vigor, field crop establishment and constant crop production (Feizi et al., 2012).

Confronting the scientific literature, the usage of high frequency electromagnetic fields and ultrasound pulsatile fields represents reasonable methods among environmental friendly seed production technologies (Bilalis et al., 2012; Liu et al., 2012; Vashisth and Nagarajan, 2010; Yaldagard et al., 2008).

The effect of high frequency electromagnetic fields upon plants is not clear yet, but some physiology aspects regard intraand extracellular ionic movements, causing the restoration of bioelectric potentials in the cell membranes and cell repolarization that activate seed germination (Vashisth and Nagarajan, 2008; Pietruszewski and Kania 2010). Plant species responses to magnetic fields are unpredictable. Martinez et al. 
(2014) showed that magnetic field seed germination of Brassica oleracea $\mathrm{L}$. was optimum at a treatment value of $17 \mathrm{mT}$ for 7.5 min resulting in increased germination percentage, germination velocity, higher fresh and dry weight of seedling compared to control. The same authors observed that a magnetic field treatment of $55 \mathrm{mT}$ for $5 \mathrm{~min}$ statistically diminished all the above presented results. It is obvious that for different types of seeds the researchers must apply differ magnetic fields treatments. In order to sustain this idea, Rosalba et al. (2014) studied the possibility of obtaining increased yields of maize grain (Zea mays L.) for human consumption by electromagnetic treatment of seeds. The intensity of the magnetic field was established at $480 \mathrm{mT}$ with different time intervals. Grain yield of 9 tons per ha where obtained at a $12 \mathrm{~min}$ exposure that statistically assured plant height increase by $0.56 \%$, stem diameter by $3.19 \%$ compared to the non-irradiated control.

Exposure to static magnetic fields between 87 to $226 \mathrm{mT}$ on mung beans seeds (Vigna radiata) was done by Mahajan and Pandey (2014), who observed that mean germination time, mean germination rate, germination rate coefficient, germination magnetic constant, transition time and water uptake was statistically improved even in off-season on all magnetic fields seed treatments. In order to improve the effect of magnetic fields on seed germination, Kubisz et al. (2012) soaked for $12 \mathrm{~h}$ in water at $20^{\circ} \mathrm{C}$ Allium cepa $\mathrm{L}$. seeds, and then exposed them to low frequency magnetic field $(20 \mathrm{mT})$. Allium cepa $\mathrm{L}$ seeds exposed for $60 \mathrm{~min}$ at $20 \mathrm{mT}$ magnetic field intensity showed an increase in the germination energy (63\% compared to $40 \%$ at control samples).

In several studies, the effect of magnetic field upon plants was observed in the dynamic from seeds to mature plants. Ahamed $e t$ al. (2013) observed the effect of magnetic field on seed germination, growth, yield and fruit quality of sweet pepper (Capsicum annuum L.). In order to follow this aspect, pepper seeds or irrigated water (separately or together) were passed through a magnetic flow tunnel. Germination of all treated seeds began one day earlier than the non-treated seeds. In the same manner, germination percentage increased by $33.7-44.9 \%$ in treated seeds related to the control. Leaf contents of chlorophyll $a$ and $b$, carotenoids and phosphorus were significantly affected by the magnetic field. In addition, fruit concentrations of phosphorus and vitamin $\mathrm{C}$ were also increased. Mahajan and Pandey (2015) studied the effect of electric and magnetic fields upon the medicinal plant bitter gourd (Momordica charantia), observing that electric field stimulates germination of Momordica charantia seeds positively at low levels with a resonating effect at $500 \mathrm{~V} / \mathrm{cm}$. The same authors observed that at higher electric fields the germination was decreased sharply $(700-1000 \mathrm{~V} / \mathrm{cm})$.

The effects on non-uniform magnetic fields on plants development and germination where conducted by Hirota $e t a l$. (1999), who noted that cucumber geotaxis was directly influenced by the strength of the magnetic field (cucumber shoot germinated in a horizontal bore leaned towards the field center).

Ultrasound pulsatile fields are presented in the scientific literature as ways of breaking seed dormancy and thick seed tegument. It is very important to set the right amount of ultrasound level, because excess is considered by some authors (Chiu and Sung 2014; Jeong et al., 2014) as decontamination agent for microbial load. The effect of ultrasound pulsatile fields depends on the frequency, intensity and duration of sound irradiation (Gordon, 1963; Rokhina et al., 2009). Pascual et al. (2004) observed that from seven treatments for removing hardheadedness and four for breaking physiological dormancy in caper seeds, acid scarification followed by the addition of a GA(3) represented the best technological solution that can be easily substituted by mechanical scarification with ultrasounds. Seed dormancy breaking, seed vigor, mean germination rate under the influence of ultrasounds was observed at different biological materials, concluding that significant statistic meanings were at all ultrasound treatments ranging between 0.11 and 2.72 $\mathrm{W} / \mathrm{cm}^{2}$ (Goussous et al., 2010; Toth et al., 2012; Wang et al., 2012).

The main goals of the present study were keen on observing: (1) the effect of high frequency pulsatile electromagnetic fields upon seed germination of Mentha $\times$ piperita L.; (2) the effect of ultrasound pulsatile fields upon seed germination of Mentha $\times$ piperita L.; (3) digital observation of seed development using photo sequencing, raster to vector enhancing with open source software; (4) the effect of high frequency pulsatile electromagnetic fields and ultrasound pulsatile fields upon main terpenes quantity.

\section{Materials and methods}

\section{Biologicalmaterial}

The biological material represented by Mentha $\times$ piperita $\mathrm{L}$. seeds, was granted by a BGCI (Botanic Gardens Conservation International) exchange between UASVM Cluj-Napoca, Romania and Hortus Botanicus Leiden, Netherlands.

\section{Experimental design}

In order to study the influence of high frequency pulsatile electromagnetic fields and ultrasound pulsatile fields on Mentha $\times$ piperita L. seed germination and quality of its essential oil, a randomized completely design with four replications was organized. Germination was recorded daily, the evaluation criteria being the presence of a radicele of at least $2 \mathrm{~mm}$. Four replicates of 100 seeds for each treatment where used. Germination tests were performed according to the International Seed Testing Association (ISTA, 2014).

The experimental factors where: (1) biological material Mentha $\times$ piperita L.; (2) germination method - distilled water (control), high frequency pulsatile electromagnetic fields (300 impulses/3 peak penetrance $-293 \mathrm{~W}$ ); ultrasound pulsatile fields $\left(1 / 2\right.$ pulses by $\left.0.5 \mathrm{~W} / \mathrm{cm}^{2}\right)$.

The experimental plot was emplaced in the laboratory of Computer Assisted Design Department, USAMV ClujNapoca, Romania, between 31.07.2014-19.09.2014. Seed germination tests were conducted in standard Linhard germinators lined with distilled water moistened cellulose wadding. During the experiment period, water level in germinator reservoir was maintained by inputs of distilled water. In order to maintain optimum germination conditions, microclimatic factors were evaluated daily with a digital multimeter, assuring constant values for all the experimental factors: relative air humidity $(60 \%)$, germination temperature $\left(25^{\circ} \mathrm{C}\right)$, light intensity (195 lux).

After germination tests, resulting seedlings where transferred in vegetation pots at the green house of Ornamental Plants Department, USAMV Cluj-Napoca, Romania, where they received standard vegetation conditions: relative air humidity 
148

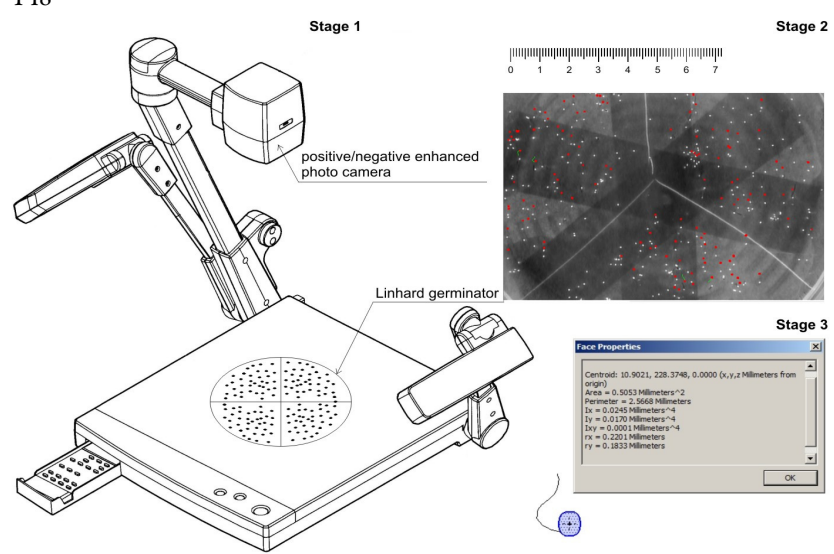

Fig. 1. Digital seed development: stage 1 - positive/negative photo capture; stage 2 - photo import and automatic vector transformation of raster documents; stage 3 - digital data collecting of seed development

(45-55\%), green house temperature $\left(20-24^{\circ} \mathrm{C}\right)$, light intensity (8000-9500 lux).

\section{Data observation}

\section{Average weight of 1000 seeds}

Before the experimental design, all the received seeds where calculated under the incidence of average weight of 1000 seeds as follows:

Average weight of 1000 seeds $=\frac{\mathrm{M}}{\mathrm{n}} 1000(\mathrm{~g})$

$\mathrm{M}=$ mass of sample seeds;

$\mathrm{n}=$ number of seeds.

For clarity reasons all the obtained results were compared to Kew (2008) seed information data base.

\section{Seed germination data observation}

The number of germinated seeds was recorded daily. The germination development was observed using a digital visual presenter equipped with a photo camera linked to a computer. The photo sequencing was made daily when positive/negative pictures where taken. After the photo capture all the images where imported in vector enhancing software that generated scale data bases like: seed area, seed perimeter, seed development on $\mathrm{x}$ and $\mathrm{y}$ radius, radicele length, hypocotyl length (Fig. 1).

Seed area, seed perimeter, seed development on $\mathrm{x}$ and $\mathrm{y}$ radius, radicele length where observed in dynamic on 5 days interval using Face Centroid and Area Properties free plugin by Schreyer (2013).

The germination percentage was calculated on the basis of 25 seeds per replicate, resulting 100 seeds per treatment.

Germination velocity index (GVI) was observed and determined based on the model of Maguire (1962) as follows:

$\mathrm{GVI}=\mathrm{G}_{1} / \mathrm{N}_{1}+\mathrm{G}_{2} / \mathrm{N}_{2}+\ldots+\mathrm{Gn} / \mathrm{Nn}$

where:

$\mathrm{G}_{1}, \mathrm{G}_{2} \ldots \mathrm{Gn}=$ number of germinated seeds each day;

$\mathrm{N}_{1}, \mathrm{~N}_{2} \ldots \mathrm{Nn}=$ number of days from sowing to last count.

Mean germination time (MGT) was evaluated using the methodology proposed by Ellis and Roberts (1981), with the final results expressed in days:

$$
M G T=\frac{\sum_{i=1}^{k} n_{i} t_{i}}{\sum_{i=1}^{k} n_{i}}
$$

where:

$t_{i}$ - time from the start of the experiment to the $i^{\text {th }}$ observation (day for the example);

$n_{i}$ - number of seeds germinated in the $i^{\text {th }}$ time (not the accumulated number, but the number correspondent to the $i^{\text {th }}$ observation);

$k$-last time of germination.

At the end of the experiment seedling vigour index (SVI) was calculated using Abdul-Baki and Anderson (1973) formula:

SVI $=$ Germination (\%) $\mathrm{x}$ [Average root length $(\mathrm{mm})+$ Average hypocotyl length (mm)].

The average length of seedling root was measured from the root tip to the insertion point of the hypocotyl. The mean hypocotyl length was measured from the base point to the insertion point of the cotyledon leaves.

\section{Chemical analysis}

Fresh mint leaves were collected from each plant and sliced (about $2 \mathrm{~mm} / \mathrm{slice}$ ). In a conical flask $1.5 \mathrm{~g}$ of sample leaves where placed with a mixture of methanol-n-hexane $(2: 1 \mathrm{v} / \mathrm{v})$. The solvent extraction method was done based on polarity issues regarding flavour compounds. In order to obtain a good exchange capacity between the analyzed material and the solvent, a stirrer was used for 10 minutes. The final stages of extraction where made by ultrasonic extraction method (USE) for 15 minutes. The maximum temperature reached at the end of extraction was less than $50^{\circ} \mathrm{C}$. The extracted liquid was separated from the residual plant material by filtration and concentrated to $1 \mathrm{ml}$ under vacuum in a rotating evaporator. $1 \mu \mathrm{L}$ of the obtained extract was injected into a gas chromatograph detector equipped with a capillary column HP-5MS of $30 \mathrm{~m}$ nominal length, nominal diameter of $0.25 \mathrm{~mm}$ and $0.25 \mu \mathrm{m}$ nominal film thickness. The software analysis tool was MSD ChemStation. The temperature applied regime was: injector temperature $-250^{\circ} \mathrm{C}$; MS quadruple temperature $-200{ }^{\circ} \mathrm{C}$; $\mathrm{MS}$ source temperature $-230{ }^{\circ} \mathrm{C}$. At the oven column were applied three temperature regime ramps as follows: the initial furnace temperature $-40^{\circ} \mathrm{C}$ kept constant for $5 \mathrm{~min}$, followed by a linear temperature increase of $2{ }^{\circ} \mathrm{C} / \mathrm{min}$ till $100{ }^{\circ} \mathrm{C}$ maintained constant for 1 minute, followed by a linear increase of $7{ }^{\circ} \mathrm{C} / \mathrm{min}$ till $200{ }^{\circ} \mathrm{C}$ maintained constant for 1 minute, followed by a linear increase of $10{ }^{\circ} \mathrm{C} / \mathrm{min}$ till $270{ }^{\circ} \mathrm{C}$ maintained constant for 5 minutes. The analysis module was full scan. The compounds were identified using the NIST database by comparing the obtained mass with the spectral mass libraries.

\section{Statistical analysis}

The statistical analysis was performed using the Excel 2002 statistical software. The post hoc Duncan test was done using DSAASTAT free VBA Macro. All the charts and graphics where made using multiple interactions between InkScape and SketchUP.

\section{Results and discussions}

Average weight of 1000 seeds was made prior to experimental plot design in order to obviate poor germination capacity due to improper seed weight. The Kew (2008) seed information database was interrogated obtaining substantial information regarding the weight of 1000 seeds of Mentha $\times$ piperita $\mathrm{L}$. at an average value of $0.0992 \mathrm{~g}$. The average weight of 1000 seeds from the experimental plot recorded the value of $0.1125 \mathrm{~g}, 13 \%$ higher than the standard Kew seed information 


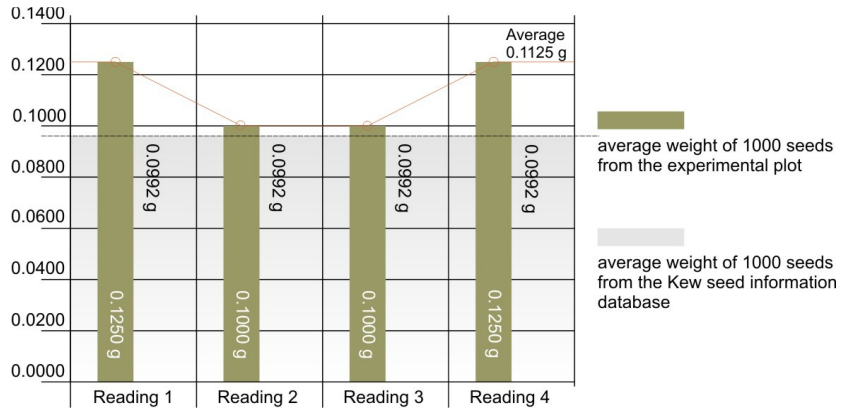

Fig. 2. Mentha $\times$ piperita L. average weight of 1000 seeds parallel to Kew seed information database (original)
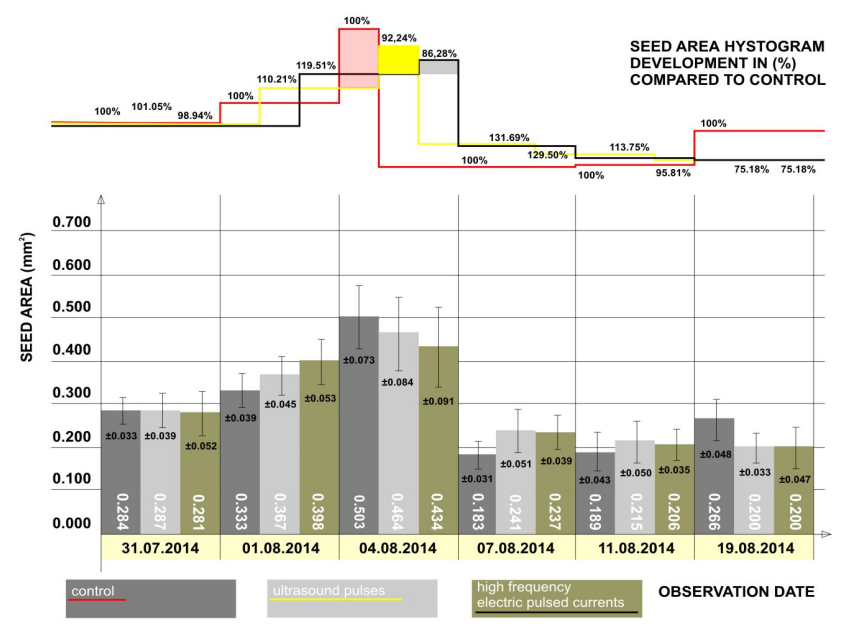

Fig. 3. Mentha $\times$ piperita L. seed area development during germination process

database about Mentha $\times$ piperita L., assuring optimum germination forecast (Fig. 2).

Mentha $\times$ piperita L. seed development was followed during germination stages in dynamic at intervals of 5 days with the help of a digital camera equipped with positive/negative photo enhancement. The main restriction of this stage consisted on the small size of mint seeds. CAD (Computer Aided Design) methods for observing seed development and germination process represented the optimum solution for this particular case and may be used for other small seed plants, due to their magnification capacity and clarity of view.

During the experiment, seed area development had an ascendant value till middle of the experiment followed by a regression related to cotyledon and root emergence (Fig. 3). For each development stage, the control was reported as reference value $(100 \%)$ assuring comparison level with all the other germination treatments. The control experimental variant revealed an average maximum seed area of $0.503 \mathrm{~mm}^{2}$ at the middle of the experiment interval. On second and third place, experimental variants stimulated by ultrasound pulses and high frequency electric pulsed currents recorded descendant values. If one regards the seed area histogram development during the germination process, it can be observed that at the end of the germination process, the control experimental variants still recorded the highest values for seed area values, creating the premise for an incomplete germination process.

Seed perimeter, directly related to seed area, revealed the same observation trends as presented above (Fig. 4).

The perimeter maximum development stage was established at the middle of the experiment interval, when the control experimental variant recorded $2.647 \mathrm{~mm}$. At the end of the

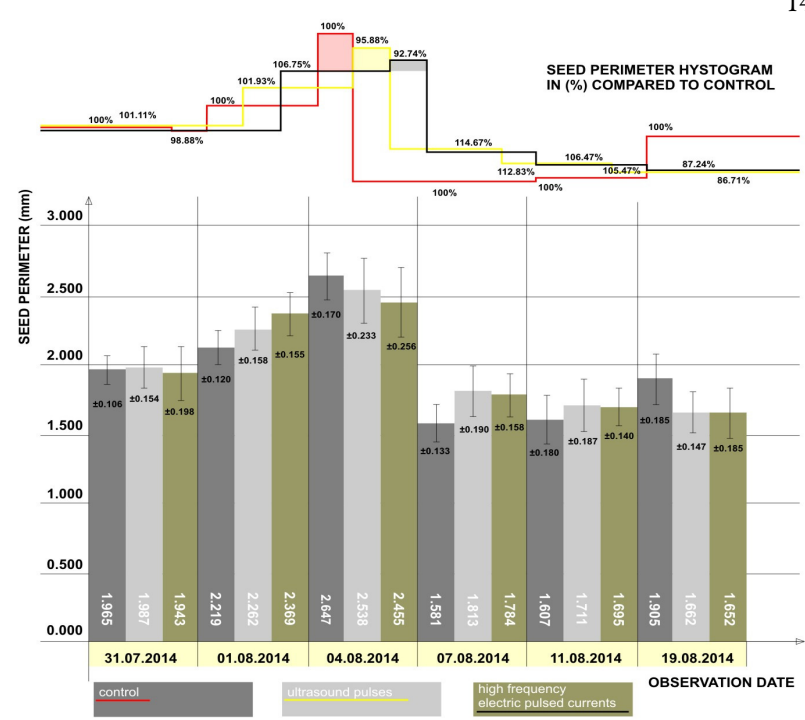

Fig. 4. Mentha $\times$ piperita L. seed perimeter development during germination process

germination process, ultrasound pulses and high frequency electric pulsed currents had descendent values, related to cotyledon and root emergence stages.

In order to set if there were any interaction relations between observed biometric measurements (seed area, seed perimeter, seed radius development on $\mathrm{x}$ and y scale) Pearson correlation coefficient was calculated for each biometric data (Tables 1, 2, 3) directly related to individual $t$ value ( $t$-Test: paired two samples for means).

Pearson correlation coefficient and $t$ value revealed the uniform development of Mentha $\times$ piperita L. seeds on $\mathrm{x}$ and $\mathrm{y}$ scale on any type of experimental variants. However, regardless the statistical significance, the highest Pearson correlation coefficient was observed at high frequency electric pulsed currents experimental variants $\left(0.99^{\circ}\right)$. On the other hand, a general known scientific fact was also demonstrated by the area and perimeter linkage development witch were positive and directly related. Overall, all the calculated Pearson correlation coefficients of the experimental variants were close to 1.00 , revealing a strong and positive correlation between different biometrical measurements (Tables 1,2,3).

Following the general dynamic of seed development, $\mathrm{x}$ scale and y scale monitoring revealed increased development stages till the middle of the study, when the experimental control obtained the highest rankings. After the maximum shape development period, a constant decrease on $\mathrm{x}$ and $\mathrm{y}$ scale was observed for the high frequency electric pulsed currents. The general dynamic chart of seed development on $\mathrm{x}$ and $\mathrm{y}$ scales concluded that control and ultrasound pulses experimental variants showed that asymptomatic seed development after the maximum development stage (4.08.2014) can occur, due to an unfinished germination process.

In order to sustain this conclusion, for each experimental variant it was calculated the germination percentage, germination velocity index (GVI) and mean germination time (MGT). With an average value of $91.75 \%$ (Fig. 7) and a significant statistical value, high frequency electric pulsed currents experimental variants obtained the highest germination percentage compared to control (47.00\%) and ultrasound pulses (64.75\%). In order to sustain the idea of quality seedlings related to high germination percentage, seedling vigour index (SVI) obtained similar data to the germination percentage (Fig. 8). 
150

Table 1. Pearson correlation coefficient and $t$ value at Mentha $\times$ piperita $\mathrm{L}$. (control)

\begin{tabular}{|c|c|c|c|c|}
\hline & Area & Perimeter & $\mathrm{x}$ scale & y scale \\
\hline Area & & 1.00 & $0.97^{\prime \prime}$ & 0.96 \\
\hline Perimeter & & & $0.97^{\prime \cdots}$ & $0.97^{\cdots}$ \\
\hline x scale & & & & $0.88^{\mathrm{ns}}$ \\
\hline y scale & & & & \\
\hline
\end{tabular}

Table 2. Pearson correlation coefficient and $t$ valueat Mentha $\times$ piperita L. (ultrasound pulses)

\begin{tabular}{|c|c|c|c|c|}
\hline & Area & Perimeter & $\mathrm{x}$ scale & y scale \\
\hline Area & & $1.00^{* * *}$ & $0.97^{\prime \prime}$ & $0.98^{* \prime}$ \\
\hline Perimeter & & & $0.98^{\cdots \cdots}$ & $0.98 * \cdots$ \\
\hline x scale & & & & $0.91^{\mathrm{ns}}$ \\
\hline y scale & & & & \\
\hline
\end{tabular}

Table 3. Pearson correlation coefficient and $t$ value at Mentha $\times$ piperita L. (high frequency electric pulsed currents)

\begin{tabular}{lccc}
\hline \multicolumn{1}{c}{ Area } & Perimeter & x scale & y scale \\
\hline Area & $1.00^{* * *}$ & $0.99^{* *}$ & $0.99^{* *}$ \\
Perimeter & & $0.99^{* *}$ & $0.99^{* *}$ \\
x scale & & $0.95^{\mathrm{ns}}$ \\
y scale \\
Note: Correlation was significant at the $\mathrm{p}<0.05 ;$ ns - statistically non significant
\end{tabular}
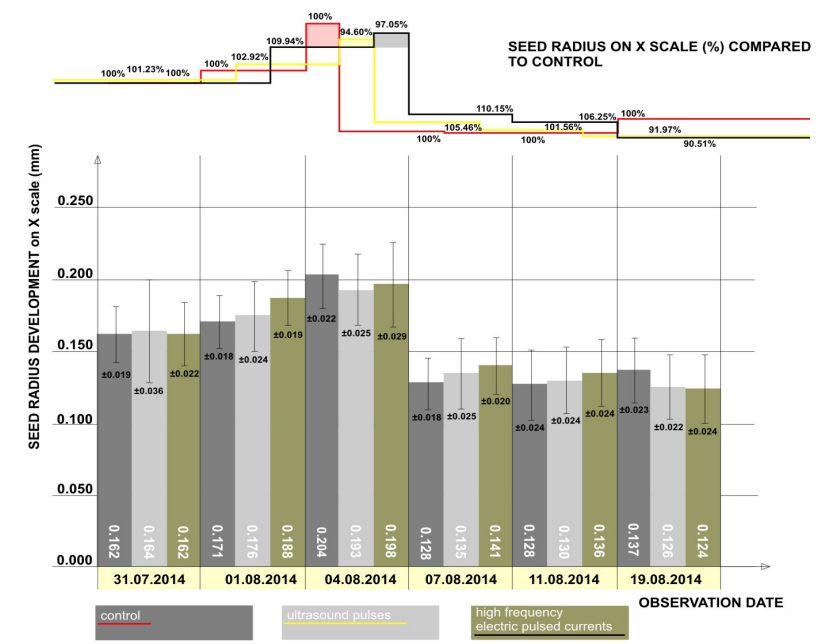

Fig. 5. Mentha $\times$ piperita L. seed radius development on $\mathrm{x}$ scale during germination process (original)

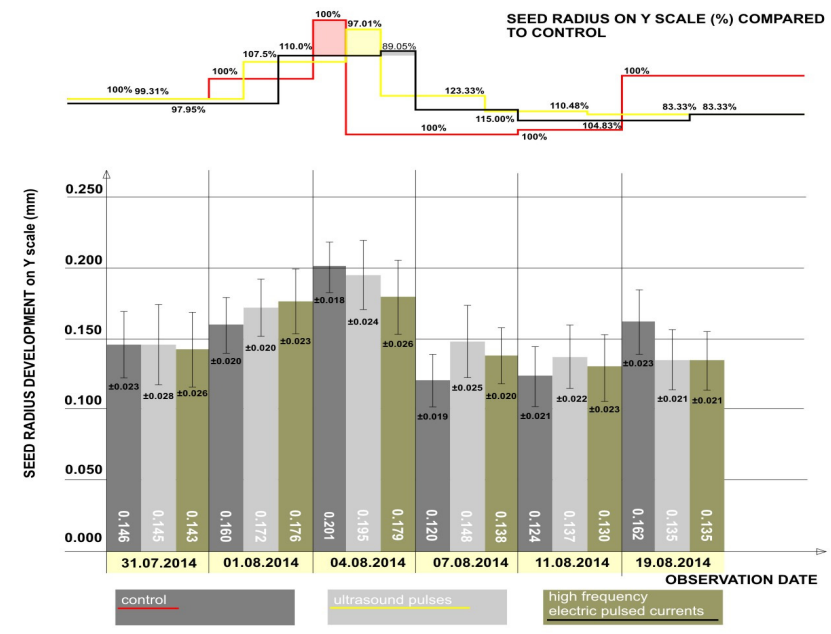

Fig. 6. Mentha $\times$ piperita L. seed radius development on y scale during germination process

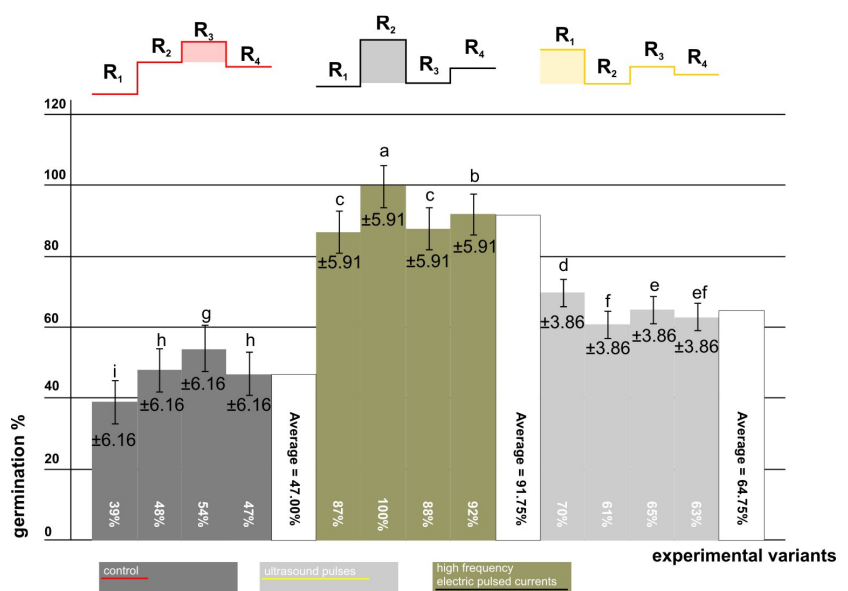

Fig. 7. Mentha $\times$ piperita L. germination percent (original)

Note: Values followed by different letters indicate significant differences $(p<0.05)$ between experimental factors according to Duncan's multiple range test
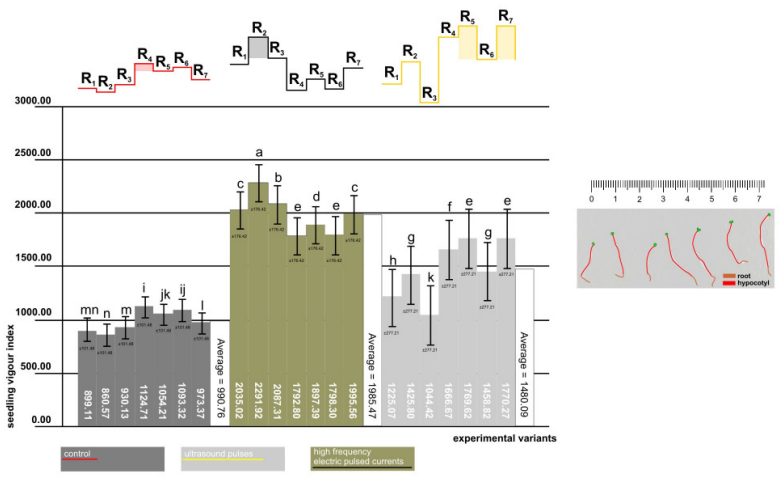

Fig. 8. Mentha $\times$ piperita L. seedling vigor index (original)

Note: Values followed by different letters indicate significant differences $(p<0.05)$ between experimental factors according to Duncan's multiple range test
$\mathbf{R}_{1} \stackrel{\mathbf{R}_{2}}{\mathbf{R}_{3}} \mathbf{R}_{4}$
$\stackrel{R_{2}}{R_{1}} \mathbf{R}_{3} \mathbf{R}^{\mathbf{R}_{4}}$
$\begin{array}{llll}\mathbf{R}_{1} & & & \mathbf{R}_{4} \\ & \mathbf{R}_{2} & \mathbf{R}_{3} & \mathbf{R}_{4}\end{array}$

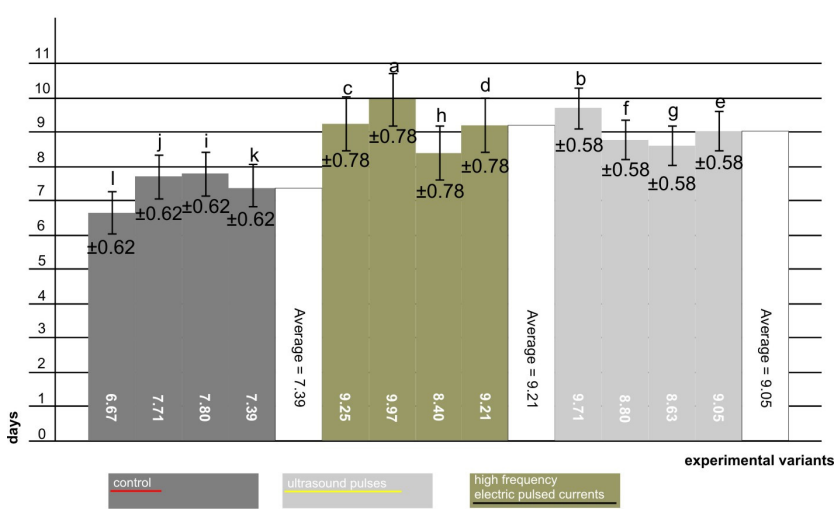

Fig. 9. Mentha $\times$ piperita L. mean germination time (original)

Note: Values followed by different letters indicate significant differences $(p<0.05)$ between experimental factors according to Duncan's multiple range test

The quality of seedlings translated by the statistical interpretation of seedling vigour index revealed high values for high frequency electric pulsed currents experimental variants (1985.47), followed by ultrasound pulses (1480.09) and control (990.76) experimental variants. Fig. 8 illustrates biometrical measurements done on one of the experimental variant, revealing the chromatic difference between root and hypocotyls. These differences were visible by free software enhancing tools based on chromatic differences of pixels in a standard 32 bit greyscale raster picture. 


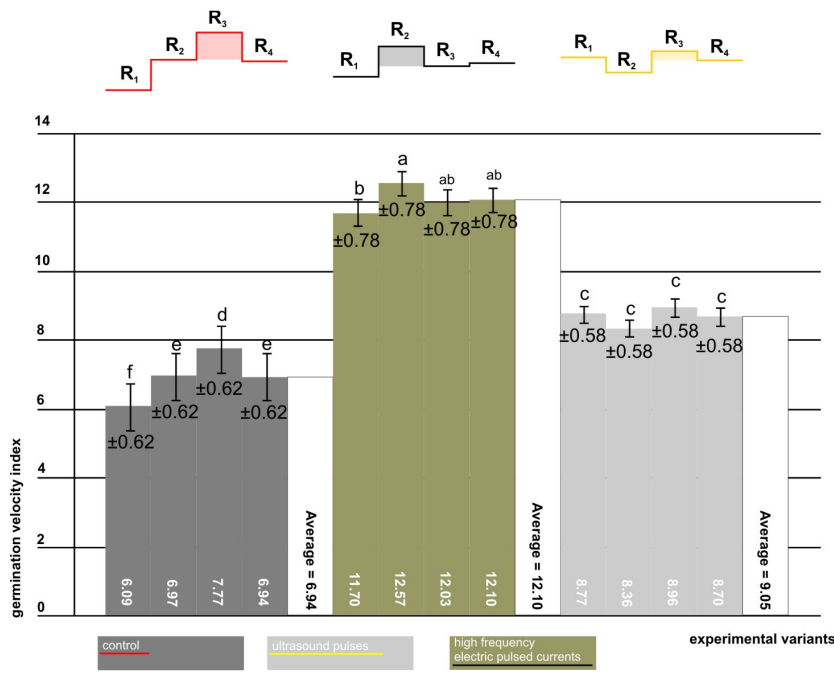

Fig. 10. Mentha $\times$ piperita L. germination velocity index (original) Note: Values followed by different letters indicate significant differences $(p<0.05)$ between experimental factors according to Duncan's multiple range test

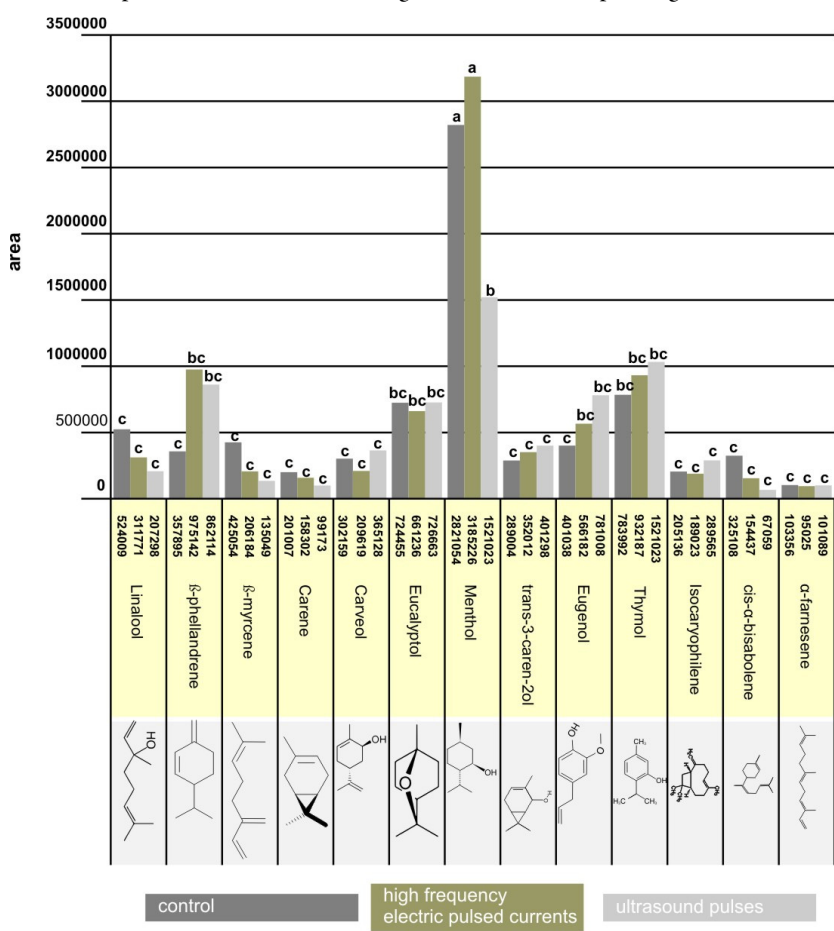

Fig. 11. Average area content of main therapeutical terpenes in Mentha $\times$ piperita L. (original)

Note: Values followed by different letters indicate significant differences $(p<0.05)$ between experimental factors according to Duncan's multiple range test

An intimate understanding of the germination process can be fulfilled by calculating MGT (mean germination time) and GVI (germination velocity index). MGT (Fig. 9) were statistically interpreted in order to sustain the idea that catalytically factors such as high frequency electric pulsed currents or ultrasound pulses, increase the value of mean germination time, with positive effects upon germination percent, seedling vigour index and germination velocity index. GVI calculation (Fig. 10) further sustained the idea of catalytically presence and its benefic effect upon germination process.

Even if mean germination time was higher for high frequency electric pulsed currents (9.21 days) or ultrasound pulses (9.05 days), compared to control experimental variants (7.39 days), the germination velocity index was higher for the above mentioned experimental variants, assuring a better germination percentage and stronger seedling vigour. More time spent on germination led to an improved germination percent.

The quality of mature plants was proved by the main therapeutically terpenes where revealed as area, compared with control experimental variants. Prior to gas chromatograph determination, soluble dry substance was determined for each experimental variant at $20{ }^{\circ} \mathrm{C}$. High frequency electric pulsed currents experimental variants obtained an average reading of $8.6 \%$ soluble dry substance, followed by ultrasound pulses (6.4\%) and control $(6 \%)$. Following this solid foundation, the highest content of terpenes was observed in high frequency electric pulsed currents and ultrasound pulses experimental variants (Fig. 11).

\section{Conclusions}

High frequency electric pulsed currents and ultrasound pulses might be considered an alternative solution for germination of problematic seeds under the influence of physical factors without chemical inputs. Seedling vigor index marks obtained at high frequency pulsatile electromagnetic fields (1985.47) and ultrasound pulsatile fields (1480.09) created the general premise for better development stages in the nursery sector. Consolidating the present results, further researches must be carried out in order to determine the optimum effect of different intensities and time amounts of high frequency electric pulsed currents and ultrasound pulses treatments on Mentha $\times$ piperita L. seeds. Considering the free software solution adopted for germination monitoring, researchers must be keen on using the open source software that are continuously improved by scientific community. Raised accumulation of main therapeutical terpenes in Mentha $\times$ piperita L. must be supervised in further studies, when microscopically imagery of glandular trichomes and their density can lead to more profound conclusions.

\section{Acknowledgements}

This paper was published under the frame of European Social Fund, Human Resources Development Operational Programme 2007-2013, project no. POSDRU/159/1.5/S/132765.

\section{References}

Adkins SW, Navie SC, Ashmore S (2007). Seeds: Biology, development and ecology. CABI Publishing.

Ahamed MEM, Elzaawely AA, Bayoumi YA (2013). Effect of magnetic field on seed germination, growth and yield of sweet pepper (Capsicum annuum L.). Asian Journal of Crop Science 5(3):286294.

Alexander C, Schreyer (2012). Architectural design with SketchUp: Component-based modeling, plugins, rendering, and scripting. Wiley \& Sons.

Bilalis D, Katsenios N, Efthimiadou A, Efthimiadis P, Karkanis A (2012). Pulsed electromagnetic fields effect in oregano rooting and vegetative propagation: A potential new organic method. Acta Agriculturae Scandinavica, Section B-Soil \& Plant Science 62(1):94-99.

Chiu KY, Sung JM (2014). Use of ultrasonication to enhance pea seed germination and microbial quality of pea sprouts. International Journal of Food Science \& Technology 49(7):1699-1706.

D'Antuono LF, Elementi S (2006). Facts and perspectives of edible Lamiaceae: flavour and health, industrial exploitation, and the consumer. Acta Hort 723:33-50. 
152

Estrelles E, Albert F, Navarro A, Prieto J, Ibars AM (2004). Germination behaviour of Labiatae SW distributed in the Iberian Peninsula. The $4^{\text {th }}$ European Conference on the conservation of wild plants. Planta Europa IV Proceedings.

Feizi H, Sahabi H, Moghaddam PR, Shahtahmassebi N, Gallehgir O, Amirmoradi S (2012). Impact of intensity and exposure duration of magnetic field on seed germination of tomato (Lycopersicon esculentum L.). Notulae Scientia Biologicae 4(1):116-120.

Fitter AH, Peat HJ (1994). The ecological flora database. J Ecol 82:415425.

Freire MM, Jham GN, Dhingra OD, Jardim CM, Barcelos RC, Valente VMM (2012). Composition, antifungal activity and main fungitoxic components of the essential oil of Mentha piperita L. Journal of Food Safety 32(1):29-36.

Gordon AG (1963). The use of ultrasound in agriculture. Ultrasonics 1(2):70-77.

Goussous SJ, Samarah NH, Alqudah AM, Othman MO (2010). Enhancing seed germination of four crop species using an ultrasonic technique. Experimental Agriculture 46(2):231-242.

Hirota N, Nakagawa J, Kitazawa K (1999). Effects of a magnetic field on the germination of plants. Journal of Applied Physics 104(8):57175719.

Jedlička J, Paulen O, Ailer Š (2014). Influence of magnetic field on germination, growth and production of tomato. Potravinarstvo $8(1): 150-154$.

Jeong M, Bae D, Bae H, Lee SI, Kim JA, Shin SC, Park S (2013). Inhibition of Botrytis cinerea spore germination and mycelia growth by frequency-specific sound. Journal of the Korean Society for Applied Biological Chemistry 56(4):377-382.

Kew RBG (2008). Seed information database (SID), version 7.1. available online http://data.kew.org/sid/

Kubisz L, Hołubowicz R, Gauza M, Li H, Hojan-Jezierska D, Jaroszyk $F$ (2012). Effect of low frequency magnetic field on germination of onion (Allium cepa L.) seeds. Acta Physica Polonica A121(1A):A49-A53.

Kumar B, Mali H, Grupta E (2014). Genetic variability, character association, and path analysis for economic traits in Menthofuran Rich Half-Sib seed progeny of Mentha piperita L. BioMed Research International 42:1-7.

Liu J-C, Gong W-H, Xiang F, Yang J-X, Fu Z-R, Peng X-M (2012). Effects of different treatments on seed germination of Mentha rotundifolia. Chinese Traditional and Herbal Drugs 43(5):10001002.

llis RA, Roberts EH (1981). The quantification of aging and survival in orthodox seeds. Seed Science and Technology 9:373-409.

Maguire JD (1962). Speed of germination-aid in selection and evaluation for seedling emergence and vigor. Crop Science 2(1):176-177.

Mahajan T, Pandey O (2014). Magnetic-time model at off-season germination. International Agrophysics 28(1):57-62.

Mahajan T, Pandey O (2015). Effect of electric and magnetic treatments on germination of bitter gourd (Momordica charantia) seed. International Journal of Agriculture and Biology 17(2):351-
356.

Martínez F, Pacheco Domínguez A, Pardo Paniagua G, Aguilar Hernández C, Ortiz Martínez E (2014). Variable magnetic field effects on seed germination of broccoli (Brassica oleracea L.). Annual Research and Review in Biology 4(24):3627-3635.

Murray MJ, Lincoln DE, Marble PM (1972). Oil composition of Mentha aquatica $\times$ M. spicata $\mathrm{F} 1$ hybrids in relation to the origin of M.xpiperita. Canadian Journal of Genetics and Cytology 14:13-29.

Onofri A (2007). Routine statistical analyses of field experiments by using an Excel extension. Proceedings 6th National Conference Italian Biometric Society: "La statistica nelle scienze della vita e dell'ambiente", Pisa, 20-22 June 2007, pp 93-96.

Parra A, Zornoza R, Conesa E, Gomez-Lopez M, Faz A (2014). Seedling emergence, growth and trace elements tolerance and accumulation by Lamiaceae species in a mine soil. Chemosphere 113:132-140.

Pascual B, San Bautista A, Imbernón A, López-Galarza S, Alagarda J, Maroto JV (2004). Seed treatments for improved germination of caper (Capparis spinosa). Seed Science and Technology 32(2):637642.

Pietruszewski S, Kania K (2010). Effect of magnetic field on germination and yield of wheat. International Agrophysics 24(3):297-302.

Pistrick K (2006). Overview of cultivated plant species in the family Labiatae. Acta Hort 723:133-141.

Rokhina EV, Lens P, Virkutyte J (2009). Low-frequency ultrasound in biotechnology: state of the art. Trends Biotechnol 27:298-306.

Rosalba Z, Claudia H, Francisco S, Arturo FD, Juan V, Cristina P, Ignacio P (2014). Electromagnetic field in corn grain production and health. African Journal of Biotechnology 13(1):76-83.

Saeed S, Tariq P (2005). Antibacterial activities of Mentha piperita, Pisum sativum and Momordica charantia. Pakistan Journal of Botany 37(4):997-1001.

Toth I, Dragomir N, Neagu A (2012). Impact of seed size and of ultrasounds on seed germination in Lotus corniculatus L. Lucrari Stiintifice: Zootehnie si Biotehnologii 45(1):422-427.

Vashisth A, Nagarajan S (2008). Exposure of seeds to static magnetic field enhances germination and early growth characteristics in chickpea (Cicer arietinum L.). Bioelectromagnetics 29:571-578.

Vashisth A, Nagarajan S (2010). Effect on germination and early growth characteristics in sunflower (Helianthus annuus) seeds exposed to static magnetic field. J Plant Physiol 167:149-156.

Wang Q, Chen G, Yersaiyiti H, Liu Y, Cui J, Wu C, He X (2012). Modeling analysis on germination and seedling growth using ultrasound seed pretreatment in switchgrass. Plos One 7(10):e47204(doi:10.1371/journal.pone.0047204).

Yaldagard M, Mortazavi SA, Tabatabaie F (2008). Application of ultrasonic waves as a priming technique for accelerating and enhancing the germination of barley seed: Optimization of method by the Taguchi approach. Journal of the Institute of Brewing 114(1):14-21. 